\title{
Mental Health and its Relationship with Social Support in Iranian Students during the COVID-19 Pandemic
}

\section{Reza Ghafari}

Tabriz University of Medical Sciences

\section{Mojgan Mirghafourvand}

Tabriz University of Medical Sciences Faculty of Nursing and Midwifery

Mahsa Rouhi

Tabriz University of Medical Sciences Faculty of Nursing and Midwifery

Shirin Osouli-Tabrizi ( $\nabla$ shirin.osouli@yahoo.com )

Tabriz University of Medical Sciences Faculty of Nursing and Midwifery

\section{Primary research}

Keywords: Mental Health, Social Support, Covid-19, Student

Posted Date: January 19th, 2021

DOI: https://doi.org/10.21203/rs.3.rs-147078/v1

License: (a) (i) This work is licensed under a Creative Commons Attribution 4.0 International License. Read Full License 


\section{Abstract}

\section{Background}

In addition to physical problems, the COVID-19 crisis continues to impose serious psychological adverse effects on people's mental health, which plays a major role in the efficiency of every community. Students, especially medical students, suffer more stress as a result of exposure to COVID induced stressors. It is, therefore, essential to measure mental health and its correlation with social support in medical students during the COVID pandemic. The present study was conducted to determine mental health status of students and its correlation with social support.

\section{Methods}

This cross-sectional study was conducted in 2020 on 280 students of Tabriz University of Medical Sciences in Iran using random sampling. Socio-demographic profile scale, Mental Health Test (GHQ-28) and the Scale of Perceived Social Support (PRQ-85) were used to collect data. Participants completed the questionnaires online.

\section{Results}

To determine the relationship between mental health and perceived social support, a general linear model was utilized considering the potential confounding variables.Mean (standard deviation) of total mental health score 26.5 (12.5) was in the acceptable range of 0 to $63.56 \%$ students suffered from a mental disorder. Mean (standard deviation) of social support score 128.2(21.0) was within the range 25 to175. According to the Pearson's correlation coefficient, there was a significant inverse correlation between social support score and total mental health score and all its subscales $[p<0.001 ; r=-0.294$ to -0.536$]$. According to the general linear model, mental health score decreased significantly with social support score $[p=0.0001 ;-0.32$ to- $0.20 ; \mathrm{Cl} 95 \% ; B=0.26]$.

\section{Conclusions}

Given the inverse relationship between social support and mental health, it is suggested to increase the level of social support for students at all times, especially during the stressful COVID-19 pandemic to improve their mental health.

\section{Background}

In December 2019, cases of unusual coronavirus-induced pneumonia were reported in Wuhan, China, and in 2020, the World Health Organization (WHO) declared the disease as a pandemic (1). The pandemic and public health measures to decelerate progression of the disease have caused profound changes in people's lifestyle and perception that can have serious impact on their mental health in addition to physical problems $(2,3)$. These impacts include a dramatic increase in mental disorders including anxiety, depression, stress, sleep disorders and fear among individuals (4). According to WHO, mental 
health is more than just the absence of mental disorders. It includes mental well-being, perception of selfefficacy, independence and autonomy, adequacy and competence, intergenerational dependence and selffulfillment of potential intellectual and emotional abilities (5). Inarguably, mental health plays a major role in the efficiency of any society (6).

As human resources, students also have a special place and therefore, mental health has a significant impact on their academic and professional progress (7). In addition, students of medicine experience more stress due to being exposed to the disease-induced stressors which are caused by fear of infection, loss of control and spread of the virus, feeling helpless due to failure to save patients, long working hours, and lack of protective equipment (8). Factors affecting mental health include gender, socio-economic status, self-esteem, religious beliefs and social support (9-12).

Social support is defined as the knowledge of the environment and a person's level of confidence that help and support will be available if needed. Social support affects people's physical and mental status, life satisfaction and quality of life and it is also known as a stress reliever (13-16). According to Alipour et al (17). Received support promotes students' mental health and social adjustment. In a study conducted in China, Cao. et al (18). Realized that the prevalence of COVID-19 has affected students' mental health and has caused varying degrees of anxiety in them. They also found that economic factors, delay in starting university, and the impact of the pandemic on daily life have increased their anxiety. Results also suggested a negative correlation between social support and symptoms of anxiety during the pandemic. Low levels of social support are strongly associated with post-traumatic stress disorder $(19,20)$.

In a study conducted by Ye et al (21). A positive correlation was shown between acute stress disorder, on the one hand, and stressful experiences and maladaptive coping strategies on the other. However, the correlation was observed to be negative when providing appropriate social support and using adaptive techniques.

Li et al (22). Showed that the pandemic outbreak intensified disease-induced consequences such as anxiety and depression in students, and in case of receiving more social support, those consequences were less aggressive. However, when proper social support was not provided, psychological symptoms developed sharply. In a study conducted in Iran on students of medicine in Tehran University of Medical Sciences, no significant difference was reported for depression and anxiety before and after the pandemic. However, the somatic symptoms of depression increased during the COVID pandemic (23). The findings of these studies collectively indicate that special attention and strategies appropriate for students are essential to deal with mental issues resulting from the pandemic.

Given the psychological impacts (24) of the pandemic and the effect of mental disorders on students' academic performance (25), mental health promotion has become a major health policy agenda in universities. Social support is a possible strategy to promote mental health. The present study was conducted to determine mental health status and its correlation with social support in Iranian students during the COVID pandemic. 


\section{Methods}

\section{Study design and Procedures}

This was a cross-sectional study conducted on all students of medical siences in Tabriz University of Medical Sciences (students of Medicine, Dentistry, Pharmacy, Nursing-Midwifery, Health and Nutrition, Rehabilitation, Medical and Paramedical Management and Information) in 2020. This study was approved by National Agency for Strategic Research in Medical Education (Code: 970270).

Inclusion criterion was being a student at Tabriz University of Medical Sciences and exclusion criteria were not providing an answer to over $20 \%$ of the questions, taking antidepressants or psychotic medication, or self-reported history of mental illness.

\section{Sampling}

Proportional random sampling was conducted based on faculties: The list of senior students of each faculty along with their telephone numbers was obtained from the Education Department. Given the sample size of the study, the number of students selected from each faculty was calculated proportionally and then using the www.random.org website, participants were randomly selected from the list of students. The selected students were called and objectives and methodology of the study were explained to them. The questionnaires were sent via WhatsApp to those who were willing to participate in the study. After filling the written consent form, the participants completed the first part of the online questionnaire anonymously. The written consent form containing information on the objectives of the study, confidentiality and exclusion from the study in case of dissatisfaction were provided to all the participants.

\section{Measures}

Socio-demographic profile scale, Mental Health Test (GHQ-28= General Health Questionnaire-28) and the Scale of Perceived Social Support (PRQ-85- Part 2= Personal Resource Questionnaire-85-Part 2) were used to collect data.

\section{Socio-demographic profile scale}

The questionnaire included questions on age, parents' education, major, employment status during studies, adequacy of family income for life expenses, place of residence, ethnicity and high-risk behaviors, such as smoking cigarettes and hookahs as well as alcohol abuse.

\section{GHQ-28}

The questionnaire was developed by Goldberg and Hillier in1979. It is one of the most well-known questionnaires for examining psychological disorders. It included four dimensions of physical symptoms, anxiety symptoms, social dysfunction, and depression symptoms, each containing 7 items. Scoring was 
performed using a four-point Likert scale: Not at all=0, slightly $=1$, Very $=2$, and extremely $=3$. Higher scores indicated lower mental health. Scores over 21 demonstrated a mental disorder (26). Validity and reliability of the questionnaire was confirmed by Taghavi (27)in Iran and the Cronbach's alpha (0.90) coefficient was reported.

\section{PRQ-85-Part 2}

The questionnaire was developed by Weinert \& Brandt in 1987 (28). To measure social support. It is composed of two parts. The second part, which was used in this study, measures perceived social support and includes 5 dimensions, namely friendship, assistance, social cohesion, value, and care. The questionnaire contains 25 items which is scored using a 7-point Likert scale from 1 to 7 (Strongly Disagree $=1$, Disagree $=2$, moderately Disagree $=3$, Undecided $=4$, Moderately Agree $=5$, Agree $=6$, Strongly Agree=7). It is worth mentioning that validity and reliability of the questionnaire was already confirmed for hemodialysis patients in Iran. Content validity and retest method were used to determine the questionnaire's validity and reliability, respectively, with a correlation coefficient of 8.0 (29)

\section{Sample size}

A sample of 253 participants was determined using G*Power with a two-sided $\otimes$ level of 0.05 and a study power of \%99 and a correlation coefficient of 0.265 based on the study by Riahi et al [30] . Given a 10\% loss of samples, the final sample size was 280 .

\section{Statistical analysis}

Data were analyzed in SPSS 24. Mean (standard deviation) and frequency (percentage) were used to describe the socio-demographic characteristics. The normality of the quantitative data was determined and confirmed by skeweness and kurtosis. The Pearson correlation test was used to determine the correlation between mental health and its components with perceived social support in the bivariate analysis. Independent t-test and one-way ANOVA were used to determine the correlation between sociodemographic characteristics and total mental health score. Then, the variables related to the total mental health score $(p<0.05)$ were entered into the general linear model as possible confounding variables along with the social support variable.

\section{Results}

Mean (SD) age of students was 22.8 (2.6) years. Less than half of the participants (43.6\%) were male and the rest were female. Over one-third of the students (38.6\%) were studying in the General Medicine program and over half of them (59.6\%) were undergraduate students of medical sciences. The majority of participants $(92.1 \%, 91.8 \%)$ reported that they did not smoke cigarettes or hookahs. About half of the participants $(47 \%)$ were the first child in a family of four members. Nearly half of the students' mothers $(45 \%)$ had an academic degree and one-fifth of the students $(21.4 \%)$ were employed. About one-third of 
the student's fathers (31\%) had academic education. Two-thirds of the students $(66.8 \%)$ had a normal body mass index (BMI). Less than one-fifth of them (15.4\%) reported their monthly income to be inadequate for life expenses (Table 1). 
Table 1

Socio-demographic characteristic of Iranian students and their relationship with mental health $(n=280)$

\begin{tabular}{|c|c|c|c|c|c|c|c|}
\hline Characteristics & $N(\%)^{\bigotimes}$ & $\begin{array}{l}\text { Mental } \\
\text { Health } \\
\text { Mean } \\
\text { (SD) }\end{array}$ & $\mathbf{P}$ & Characteristics & $N(\%)^{\bigotimes}$ & $\begin{array}{l}\text { Mental } \\
\text { Health } \\
\text { Mean } \\
\text { (SD) }\end{array}$ & $\mathbf{P}$ \\
\hline Age & & & $0.501^{\dagger}$ & \multicolumn{2}{|c|}{ Mother's education } & & $0.869^{\ddagger}$ \\
\hline Lower than 22 & $\begin{array}{l}160 \\
(57.1)\end{array}$ & $\begin{array}{l}26.0 \\
(12.0)\end{array}$ & & Illiterate & $16(5.7)$ & $\begin{array}{l}25.9 \\
(11.7)\end{array}$ & \\
\hline 22 and more & $\begin{array}{l}120 \\
(42.9)\end{array}$ & $\begin{array}{l}27.1 \\
(13.0)\end{array}$ & & Primary & $31(11.1)$ & $\begin{array}{l}25.0 \\
(12.6)\end{array}$ & \\
\hline Gender & & & $0.401^{\dagger}$ & Secondary & $\begin{array}{l}33 \\
(11.8)\end{array}$ & $\begin{array}{l}28.3 \\
(13.4)\end{array}$ & \\
\hline Male & $\begin{array}{l}122 \\
(43.6)\end{array}$ & $\begin{array}{l}26.5 \\
(13.1)\end{array}$ & & High school & $\begin{array}{l}74 \\
(26.4)\end{array}$ & $\begin{array}{l}27.0 \\
(12.9)\end{array}$ & \\
\hline Female & $\begin{array}{l}158 \\
(56.4)\end{array}$ & $\begin{array}{l}26.6 \\
(12.1)\end{array}$ & & University & $\begin{array}{l}125 \\
(45.0)\end{array}$ & $\begin{array}{l}26.3 \\
(12.2)\end{array}$ & \\
\hline $\begin{array}{l}\text { Educational } \\
\text { grade }\end{array}$ & & & $0.749^{\dagger}$ & \multicolumn{2}{|c|}{ Father's education } & & $0.545^{\ddagger}$ \\
\hline Bachelor & $167(59.6)$ & $\begin{array}{l}26.7 \\
(12.4)\end{array}$ & & Illiterate & $5(1.8)$ & $\begin{array}{l}35.2 \\
(17.07)\end{array}$ & \\
\hline Doctorate & 108(38.6) & $\begin{array}{l}26.5 \\
(12.9)\end{array}$ & & Primary & $25(8.9)$ & $\begin{array}{l}23.8 \\
(11.7)\end{array}$ & \\
\hline Smoking & & & $0.003^{\dagger}$ & Secondary & $24(8.6)$ & $\begin{array}{l}26.0 \\
(11.5)\end{array}$ & \\
\hline Yes & $22(7.9)$ & $\begin{array}{l}34.1 \\
(15.4)\end{array}$ & & High school & $3(1.1)$ & $\begin{array}{l}27.6 \\
(7.6)\end{array}$ & \\
\hline No & $\begin{array}{l}258 \\
(92.1)\end{array}$ & $\begin{array}{l}25.9 \\
(12.1)\end{array}$ & & Diploma & $\begin{array}{l}76 \\
(27.1)\end{array}$ & $\begin{array}{l}27.5 \\
(11.7)\end{array}$ & \\
\hline Hookah & & & $0.228^{\dagger}$ & University & $\begin{array}{l}147 \\
(52.5)\end{array}$ & $\begin{array}{l}26.3 \\
(13.2)\end{array}$ & \\
\hline Yes & $23(8.2)$ & $\begin{array}{l}25.7 \\
(11.1)\end{array}$ & & \multicolumn{2}{|c|}{ Father's occupation } & & $0.277^{\ddagger}$ \\
\hline No & $\begin{array}{l}257 \\
(91.8)\end{array}$ & $\begin{array}{l}26.6 \\
(12.7)\end{array}$ & & Unemployed & $8(2.9)$ & $\begin{array}{l}32.1 \\
(16.8)\end{array}$ & \\
\hline Smoking duratic & (Month) & & $0.217^{\ddagger}$ & Worker & $5(1.8)$ & $\begin{array}{l}19.6 \\
(8.1)\end{array}$ & \\
\hline
\end{tabular}

${ }^{\nabla}$ Number (Percent); ${ }^{\dagger}$ Independent t-test; ${ }^{\ddagger}$ One Way ANOVA 


\begin{tabular}{|c|c|c|c|c|c|c|c|}
\hline Characteristics & $N(\%)^{\rrbracket}$ & $\begin{array}{l}\text { Mental } \\
\text { Health } \\
\text { Mean } \\
\text { (SD) }\end{array}$ & $\mathbf{P}$ & Characteristics & $N(\%)^{囚}$ & $\begin{array}{l}\text { Mental } \\
\text { Health } \\
\text { Mean } \\
\text { (SD) }\end{array}$ & $\mathbf{P}$ \\
\hline$<12$ & $14(5)$ & $\begin{array}{l}29.4 \\
(13.3)\end{array}$ & & Employee & $\begin{array}{l}72 \\
(25.7)\end{array}$ & $\begin{array}{l}25.05 \\
(12.7)\end{array}$ & \\
\hline $12-36$ & $6(2.1)$ & $\begin{array}{l}27.6 \\
(13.1)\end{array}$ & & Physician & $16(507)$ & $\begin{array}{l}27.4 \\
(11.5)\end{array}$ & \\
\hline$>36$ & $7(2.5)$ & $\begin{array}{l}39.5 \\
(14)\end{array}$ & & Freelance & $\begin{array}{l}172 \\
(61.4)\end{array}$ & $\begin{array}{l}26.8 \\
(12.3)\end{array}$ & \\
\hline \multicolumn{2}{|c|}{ Number of family members } & & $0.343^{\ddagger}$ & \multicolumn{2}{|c|}{ Number of child in family } & & $0.177^{\ddagger}$ \\
\hline$\leq 3$ & $43(15.4)$ & $\begin{array}{l}25.7 \\
(13.2)\end{array}$ & & 1 & $21(7.5)$ & $\begin{array}{l}24.5 \\
(12.9)\end{array}$ & \\
\hline 4 & $\begin{array}{l}146 \\
(52.1)\end{array}$ & $\begin{array}{l}27.8 \\
(12.8)\end{array}$ & & 2 & $\begin{array}{l}151 \\
(53.9)\end{array}$ & $\begin{array}{l}27.9 \\
(12.7)\end{array}$ & \\
\hline 5 & $51(18.2)$ & $\begin{array}{l}25.4 \\
(12.9)\end{array}$ & & 3 & $\begin{array}{l}57 \\
(20.4)\end{array}$ & $\begin{array}{l}26.1 \\
(13.0)\end{array}$ & \\
\hline$\geq 6$ & $40(14.3)$ & $\begin{array}{l}24.2 \\
(9.8)\end{array}$ & & $\geq 4$ & $\begin{array}{l}51 \\
(18.2)\end{array}$ & $\begin{array}{l}23.8 \\
(10.9)\end{array}$ & \\
\hline \multicolumn{2}{|c|}{ Employed with education } & & $0.002^{\dagger}$ & \multicolumn{2}{|c|}{ Birth order in family } & & $0.787^{\ddagger}$ \\
\hline Yes & $60(21.4)$ & $\begin{array}{l}30.03 \\
(13.1)\end{array}$ & & 1 & $\begin{array}{l}133 \\
(47.5)\end{array}$ & $\begin{array}{l}27.3 \\
(13.3)\end{array}$ & \\
\hline No & $\begin{array}{l}220 \\
(78.6)\end{array}$ & $\begin{array}{l}25.6 \\
(12.2)\end{array}$ & & 2 & $\begin{array}{l}87 \\
(31.1)\end{array}$ & $\begin{array}{l}25.8 \\
(11.3)\end{array}$ & \\
\hline \multicolumn{2}{|c|}{ Mothers occupation } & & $0.228^{\dagger}$ & 3 & $\begin{array}{l}29 \\
(10.4)\end{array}$ & $\begin{array}{l}25.4 \\
(13.1)\end{array}$ & \\
\hline Employed & $89(31.8)$ & $\begin{array}{l}28.2 \\
(13.6)\end{array}$ & & $\geq 4$ & $\begin{array}{l}29 \\
(10.4)\end{array}$ & $\begin{array}{l}26.3 \\
(12.6)\end{array}$ & \\
\hline Housewife & $191(68.2)$ & $\begin{array}{l}25.8 \\
(11.9)\end{array}$ & & \multicolumn{3}{|c|}{$\begin{array}{l}\text { Adequacy of income for family } \\
\text { expenses }\end{array}$} & $0.238^{\ddagger}$ \\
\hline BMI (Kg/m2) & & & $0.003^{\ddagger}$ & Adequate & $\begin{array}{l}73 \\
(26.1)\end{array}$ & $\begin{array}{l}26.3 \\
(12.5)\end{array}$ & \\
\hline $\begin{array}{l}\text { Underweight } \\
(<18.5)\end{array}$ & $17(6.1)$ & $\begin{array}{l}24.9 \\
(8.2)\end{array}$ & & $\begin{array}{l}\text { Fairly } \\
\text { adequate }\end{array}$ & $\begin{array}{l}167 \\
(58.6)\end{array}$ & $\begin{array}{l}25.9 \\
(12.4)\end{array}$ & \\
\hline $\begin{array}{l}\text { Normal }(18.5- \\
24.9)\end{array}$ & $\begin{array}{l}187 \\
(66.8)\end{array}$ & $\begin{array}{l}25 \\
(11.2)\end{array}$ & & Inadequate & $\begin{array}{l}43 \\
(15.4)\end{array}$ & $\begin{array}{l}26.6 \\
(12.6)\end{array}$ & \\
\hline
\end{tabular}

${ }^{\mathbb{N}}$ Number (Percent); ${ }^{\dagger}$ Independent t-test; ${ }^{\ddagger}$ One Way ANOVA 


\begin{tabular}{|c|c|c|c|c|c|c|c|}
\hline Characteristics & $N(\%)^{\bigotimes}$ & $\begin{array}{l}\text { Mental } \\
\text { Health } \\
\text { Mean } \\
\text { (SD) }\end{array}$ & $\mathbf{P}$ & Characteristics & $N(\%)^{\bigotimes}$ & $\begin{array}{l}\text { Mental } \\
\text { Health } \\
\text { Mean } \\
\text { (SD) }\end{array}$ & $\mathbf{P}$ \\
\hline $\begin{array}{l}\text { Overweight } \\
(25.0-29.9)\end{array}$ & $64(22.9)$ & $\begin{array}{l}30.0 \\
(15.5)\end{array}$ & & & & & \\
\hline Obese $(\geq 30)$ & $9(3.2)$ & $\begin{array}{l}36.3 \\
(13.5)\end{array}$ & & & & & \\
\hline
\end{tabular}

Mean (SD) of total mental health score was 26.5 (12.5) in the obtainable range score of 0 to 63 . More than half of the students (56\%) suffered from a mental disorder. The highest mean score was obtained for social performance [8.6 (2.5)] and the lowest was for depression [4.9 (4.5)]. Mean (SD) of social support score was 128.2 (21.0) within the range score of 25 to175. According to the Pearson's correlation coefficient, there was a significant inverse correlation between social support score and total mental health score and all its subscales $[r=-0.294$ to $-0.536 ; P<0.001]$ (Table 2 ).

Table 2

The status of mental health and its domains and social support and their correlation among Iranian students $(n=280)$

\begin{tabular}{|lllll|}
\hline variable & $\begin{array}{l}\text { Mean } \\
\text { (SD) }\end{array}$ & $\begin{array}{l}\text { Obtained score } \\
\text { range }\end{array}$ & $\begin{array}{l}\text { Obtainable score } \\
\text { range }\end{array}$ & $\begin{array}{l}\text { Correlation with social } \\
\text { support } \\
\mathbf{r}(\mathbf{p}) \mathbb{}\end{array}$ \\
\hline $\begin{array}{l}\text { Total score of mental } \\
\text { health }\end{array}$ & $\begin{array}{l}26.5 \\
(12.5)\end{array}$ & $6-70$ & $0-84$ & $-0.48(<0.001)$ \\
\hline Physical health & $6.1(3.8)$ & $0-21$ & $0-21$ & $-0.29(<0.001)$ \\
\hline Anxiety & $6.8(4.6)$ & $0-21$ & $0-21$ & $-0.32(<0.001)$ \\
\hline Depression & $4.9(4.5)$ & $0-21$ & $0-21$ & $-0.54(<0.001)$ \\
\hline Social function & $8.6(2.5)$ & $4-20$ & $0-21$ & $-0.37(<0.001)$ \\
\hline Social support & 128.2 & $60-168$ & $25-175$ & - \\
\hline & $(21.04)$ & & & \\
\hline Pearson correlation test & & & \\
\hline
\end{tabular}

According to the one-way ANOVA and independent t-test, there was, statistically, a significant correlation between mental health and the variables of smoking $(P=0.003)$, employment during studies $(P=0.002)$, and BMI $(P=0.003)$. These variables were entered into the general linear model along with the social support variable. According to the general linear model, mental health score decreased significantly with increasing social support score $[B=0.26 ; C l 95 \%=-0.32$ to- $0.20 ; P<0.001]$ (Table 3 ). 
Table 3

Relationship between social support and metal health among Iranian students based on General Linear Model $(n=280)$

\begin{tabular}{|lll|}
\hline Variable & B (95\% Confidence Interval) & P-value \\
\hline Social support & $-0.26(-0.32$ to -0.20$)$ & $<0.001$ \\
\hline BMI $\left(\mathrm{Kg} / \mathrm{m}^{2}\right)$ & & \\
\hline Underweight $(<18.5)$ & $-5.07(-14.13$ to 3.98$)$ & 0.271 \\
\hline Normal (18.5-24.9) & $-5.09(-12.63$ to 2.45$)$ & 0.185 \\
\hline Overweight $(25.0-29.9)$ & $-2.67(-10.39$ to -5.04$)$ & 0.496 \\
\hline Obese $(\geq 30)($ Reference $)$ & 0 & \\
\hline Employee with education & & \\
\hline Yes & $1.63(-1.66$ to 4.93$)$ & \\
\hline No (Reference) & 0 & 0.329 \\
\hline Smoking & & \\
\hline Yes & $4.90(-0.02$ to 9.81$)$ & \\
\hline No (Reference) & 0 & \\
\hline
\end{tabular}

\section{Discussion}

In addition to physical health concerns, COVID-19 causes psychological disorders and affects mental health of people in different communities (2). Students' mental health is a major public health concern. It is also important to examine and prevent mental health disorders during the COVID-19 pandemic (31). Given these conditions, the aim of the present study was to investigate mental health and its correlation with social support in Iranian students during the COVID-19 pandemic. Results of this study showed that $56 \%$ of students suffered from a mental disorder and received only average social support. There was a significant relationship between social support and mental health.

In this study, over half of the students suffered from a mental disorder which is higher compared to the pre-COVID-19 period given the studies conducted in this field. For instance, in a study carried out by Solhi et al (32). Before the COVID-19 pandemic on Iranian students of medicine, only $14.7 \%$ percent suffered from poor mental health. Furthermore, in a study conducted on Payam-e Noor students in West Azerbaijan, Iran, $46.6 \%$ percent of students suffered from mental disorders which were more common among female students (33). Results of a meta-analysis performed by zare et al (34). To investigate mental health of Iranian students using GHQ-28 questionnaire. Revealed that general prevalence of mental disorders among Iranian students was $32.3 \%$. In a study conducted to investigate depression and anxiety among students of medicine at Tehran University of Medical Sciences during the COVID-19 
pandemic, $38.1 \%$ mild to severe anxiety and $27.4 \%$ depression was reported. The most common symptoms reported were changes in sleep patterns and anxiety. In addition, higher level of anxiety was associated with female gender, having COVID symptoms, and low grade point average (23). Given the results of previous studies, mental disorders have been on the rise among Iranian students during the COVID pandemic.

There was no significant difference between mental health of male and female students in this study. In another study conducted during the COVID pandemic on 69054 French students, severe symptoms of mental problems were reported in students who were under quarantine. According to this study, $11.4 \% \%$ reported suicidal thoughts, $16.1 \% \%$ reported severe depression, $27.5 \%$ suffered from high levels of anxiety and only $12.45 \%$ had seen a doctor. This study indicates that health issues during the COVID pandemic were more prevalent among French students (31). In a study on 476 Bangladeshi students during the COVID pandemic, the authors shared standard questionnaires with students through social media and found that $15 \%$ of the students showed symptoms of medium depression and $18.1 \%$ suffered from severe depression. In addition, depression was more common among students who studied in tuitionpaying universities. Financial problems were reported to be a cause of depression and anxiety among students (4).

Results of this study indicated a significant inverse correlation between mental health and social support in Iranian students. The correlation between social support and mental health has been investigated in other studies in the pre-COVID period and a significant statistical relation was reported between them (35, 36). Results of a study on 450 Chinese students of various majors during the COVID pandemic indicated a positive correlation between COVID-induced stressors and psychological symptoms such as depression and anxiety and there was a negative correlation between social support and psychological symptoms (22). Results of another study conducted on 2020 individuals during the COVID pandemic indicated that those who experienced isolation and loneliness reported higher rates of depression. In addition, lower social support was significantly associated with an increased risk of depression and poor sleep quality (37). Given the importance of social support and the COVID-induced mental health crisis, conditions must be created so that students feel there are people who can support them in difficult situations. Special plans should also be developed to improve mental health, as well as identify and refer students to counseling centers $(11,25,38)$.

The strengths of the present study were random sampling and including students from all faculties of Tabriz University of Medical Sciences, both of which strengthened the generalizability of the results. The cross-sectional nature of the study was one of its limitations and the correlations shown here failed to accurately indicate a causal relationship. Therefore, conducting similar studies on different societies with different cultures is recommended for future research.

\section{Conclusions}


Results of the present study indicated the high prevalence of mental disorders in students, which highlights the importance of screening and designing appropriate interventions in this regard.

Considering the inverse correlation between social support and mental health in this study, it is suggested to promote students' mental health by providing them with higher levels of social support, especially during the stressful COVID-19 pandemic.

\section{Abbreviations}

WHO: World Health Organization; Covid-19: Coronavirus disease; PRQ-85- Part 2: Personal Resource Questionnaire-85-Part 2; GHQ-28: General Health Questionnaire-28

\section{Declarations}

\section{Ethic approval and consent of participate}

This study was approved by National Agency for Strategic Research in Medical Education (Code: 970270). The written consent form containing information on the objectives of the study, confidentiality and exclusion from the study in case of dissatisfaction were provided to all the participants.

Consent for publication

Not applicable.

\section{Availability of data and materials}

The datasets used and/or analysed during the current study are available from the corresponding author on reasonable request.

Competing interests

The author(s) declared no potential conflicts of interest with respect to the research, authorship, and/or publication of this article.

\section{Funding}

This study was financially supported by National Agency for Strategic Research in Medical Education. The funder had no role in the study design, data collection and analysis or manuscript production.

\section{Authors' contributions}

RG, MM and SHO contributed to design. MM statistical analysis. MM and SHO participate in most of the study steps. MR, MM, SHO prepared the manuscript. All authors have read and approved the content of the manuscript. 


\section{Acknowledgment}

We sincerely thank all students who participated in this study.

\section{References}

1. WHO. WHO Timeline - COVID-19. World Health Organization COVID-19. 2020.

2. Salari N, Hosseinian-Far A, Jalali R, Vaisi-Raygani A, Rasoulpoor S, Mohammadi M, et al. Prevalence of stress, anxiety, depression among the general population during the COVID-19 pandemic: a systematic review and meta-analysis. Global Health. 2020;16(1):57.

3. Bueno-Notivol J, Gracia-García P, Olaya B, Lasheras I, López-Antón R, Javier S. revalence of depression during the COVID-19 outbreak: a meta-analysis of community-based studies. Int. J. Clin. Health Psychol. 2020.

4. Islam MA, Barna SD, Raihan H, Khan MNA, Hossain MT. Depression and anxiety among university students during the COVID-19 pandemic in Bangladesh: A web-based cross-sectional survey. PLOS ONE. 2020;15(8):e0238162.

5. WHO. Mental health: New understanding, new hope. Switzerland: World Health Organization Geneva; 2001.

6. Abbasi A. The examination of students mental health in yassoj university of medical science and health services. Teb va Tazkieh. 2001(43):34-8.

7. Ziaei V, Moein A, Jamali M, Faghih A, Malekinezhad M. G N. The Examination of Students Mental Health in Tehran University of Medical Sciences and Health Services From 1373 to 1378 at the Beginning of Entering on the Basis of Scl-90-R Test and Comparison of its Results with Interview. Teb va Tazkieh. 2001(43):25-33.

8. Xie L, Luo H, Li M, Ge W, Xing B, Miao Q. The immediate psychological effects of Coronavirus Disease 2019 on medical and non-medical students in China. J Public Health. 2020;65(8):1445-53.

9. Sodeify R, Moghaddam Tabrizi F. Nursing Students' Perceptions of Effective Factors on Mental Health: A Qualitative Content Analysis. Int J Community Based Nurs Midwifery. 2020;8(1):34-44.

10. Soltanian A, Bahreiny F, Namazi S, Amiri M, Ghaedi H, Kohan G. Mental Health of high school students and its effective factors in Bushehr Province. Iran South Med J. 2005;7(2):173-82.

11. Mehri A. Sedighy somekoochak Z. assesment of mental health state and some related factors among students of zabzevar university in 2010. Medical science journal of islamic azad university. 2012;21(4).

12. Ghaderi M, Hardani F, Nasiri M, Fakouri E. Assessment of Mental Health and its Related Factors in Jiroft students of Higher Education Centers in 2013. Journal of Rafsanjan University of Medical Sciences. 2015;13(10):949-60.

13. Bruwer B, Emsley R, Kidd M, Lochner C, Seedat S. Psychometric propertie of the Multidimensional Scale of Perceived Social Support in youth. Compr Psychiatry. 2008;49:195-201. 
14. Teh W, Shahwan S, Abdin E, Zhang Y, Sambasivam R, Devi F, et al. Confirmatory Factor Analysis and Measurement Invariance of the Multidimensional Scale of Perceived Social Support in Young Psychiatric and Non-Psychiatric Asians. Ann Acad Med Singap. 2019;48:314-20.

15. Tajalli P, Sobhi A, Ganbaripanah A. The relationship between daily hassles and social support on mental health of university students. Procedia Soc Behav Sci. 2010;5:99-103.

16. Gloria.Bird. Rhonda.Harris. A comparison of role strain and coping strategies by gender and family structure among early adolescents. J Early Adolesc. 1990;10(2):141-58.

17. Alipour $S$, Sahaghi $H$, Jelodari A. The relationship between perceived social support and Academic self-efficacy with social adjustment. Development Strategies in Medical Education. 2015;2(1):26-37.

18. Wenjun Cao Z, Fang G, Hou xinvong, Xu. Dong J. he psychological impact of the COVID-19 epidemic on college students in China. Psychiatry Res. 2020;112934(278).

19. Ozer EJ, Best SR, Lipsey TL, DS W. redictors of posttraumatic stress disorder and symptoms in adults: a meta-analysis. Psychol Bull. 2003;129(1):52.

20. Brewin CR, Andrews B, Valentine JD. Meta-analysis of risk factors for posttraumatic stress disorder in trauma-exposed adults. J Consult Clin Psychol. 2000;68(5):748.

21. Ye Z, Yang X, Zeng C, Wang Y, Shen Z, Li X. et al. Resilience, Social Support, and Coping as Mediators between COVID-19-related Stressful Experiences and Acute Stress Disorder among College Students in China. Applied Psychology: Appl Psychol Health Well-Being.2020; 12211. Doi:

10.1111/aphw.12211.

22. Li X, Wu H, Meng F, Li L, Wang Y, Zhou M. Relations of COVID-19-Related Stressors and Social Support With Chinese College Students' Psychological Response During the COVID-19 Pandemic. Front Pssychiatry. 2020;11(1084).

23. Amin N, Alborz S, Faezeh A, MohammadSaeid K, Reyhaneh A, Nazila S. Depression and Anxiety among Iranian Medical Students during COVID-19 Pandemic. Iran. J. Psychiatry. 2020;15(3).

24. Xiong J, Lipsitz O, Nasri F, Lui LMW, Gill H, Phan L, et al. Impact of COVID-19 pandemic on mental health in the general population: A systematic review. J Affect Disord. 2020;277:55-64.

25. Kecojevic A, Basch CH, Sullivan M, Davi NK. The impact of the COVID-19 epidemic on mental health of undergraduate students in New Jersey, cross-sectional study. PLOS ONE. 2020;15(9):e0239696.

26. Namdar H, Ebrahimi H, Sahebihagh Mh, Arshadi M. Mental health status and its relationship with accademic acheivment in students of tabriz nursing-midwifery school. Iranian Journal of Medical Education. 2013;13(2):146-52.

27. taghavi S. validity and reliability of the general health questionare (GHQ-28) in college students of shiraz university. J Psychol. 2002;5(4 (20)):381-98.

28. Weinert C, Brandt PA. Measuring Social Support with the Personal Resource Questionnaire. West J Nurs Res. 1987;9(4):589-602.

29. Rambod M, Rafii F. Perceived Social Support and Quality of Life in Iranian Hemodialysis Patients. J Nurs Scholarsh. 2010;42:242-9. 
30. Riahi ME, Aliverdinia A, Pourhossein Z. Relationship between Social Support and Mental Health. Soc Welf. 2011;10(39):85-121.

31. Wathelet M, Duhem S, Vaiva G, Baubet T, Habran E, Veerapa E, et al. Factors Associated With Mental Health Disorders Among University Students in France Confined During the COVID-19 Pandemic. JAMA. 2020;3(10):e2025591-e.

32. Solhi M, Pirouzeh R. Rahimi Khalifeh Kend z. Self-assessment of Mental Health Among Students of Iran University of Medical Sciences. Iran J Health Educ Health Promot. 2019;7(3):339-48.

33. Mokhtari M. A Study of Mental Health of University Students in West Azerbaijan in Iran. Int j sci: basic appl. 2012;2:13188-94.

34. Zare N, Parvareh M, Noori B, Namdari M. Mental health status of Iranian university students using the GHQ-28: a meta-analysis. Scientific Journal of Kurdistan University of Medical Sciences. 2016;21(4):1-16.

35. azadi S, Azad H. The Correlation of Social Support, tolerance and Mental Health in Children of Martyrs and war-disabled in Universities of Ilam. Iranian Journal of War Public Health. 2011;3(4):4858.

36. Hamid P, Ahmad H, Leili P. A Survey on the relation between Social Support and Mental Health in Students of Tehran University. Health Serv Res. 2010;6(2):301.

37. Grey I, Arora T, Thomas PhD. Cpsychol J, Saneh A, Tomhe P, Abi Habib R. The role of perceived social support on depression and sleep during the COVID-19 pandemic. Psychiatry Res. 2020;293:113452.

38. Hajebi A, Faridnia P. The Relationship between mental health and social support in health staffs of Bushehr oil industry. Iran South Med J. 2009;12(1):67-74. 